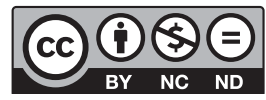

Estudos Teológicos foi licenciado com uma Licença Creative Commons Atribuição - NãoComercial - SemDerivados 3.0 Não Adaptada

http://dx.doi.org/10.22351/et.v60i3.4043

\title{
Afroteontologia: estudo sobre Deus SEGUNDO A COSMOPERCEPÇÃO DAS TRADIÇÕES DE MATRIZ AFRICANA ${ }^{1}$
}

\author{
Afrotheontology: study on God \\ according to the world-sense of the traditions of African origin
}

\section{Hendrix Silveira ${ }^{2}$ Oneide Bobsin ${ }^{3}$}

Resumo: O presente artigo é fruto de nossos estudos sobre a afroteontologia, ou seja, estudo sobre Deus de acordo com a teologia das tradições de matriz africana, que temos chamado de afroteologia. Utilizamos como método a exunêutica, ou seja, nos valemos de uma epistemologia afrocentrada com interpretação que contempla a vivência nas comunidades tradicionais de terreiro. Este trabalho visa contribuir na construção de uma sistematização do conhecimento afroteológico no intuito de contribuir para a formação dos vivenciadores, subsidiando-os no combate ao racismo religioso, assim como fornecer informações para professores do Ensino Religioso e também para pesquisadores da área de Ciências da Religião e Teologia. Pudemos aqui construir uma visão de Deus nas tradições de matriz africana a partir de um estudo de fontes africanas e afro-brasileiras, além da tradição oral, principal meio de transmissão do conhecimento pelas comunidades tradicionais de terreiro.

Palavras-chave: Teontologia. Afroteologia. Deus. Religiões afro-brasileiras.

Abstract: This paper is the result of our studies on afrotheontology, that is, a study on God according to the theology of traditions of African origin, which we have called Afrotheology. We use eshuneutics as a method, that is, we use an Afrocentric epistemology with interpretation that contemplates the experience in traditional African communities. This work aims to contribute to the construction of a systematization of afrotheological knowledge in order to contribute to the training of the experience, supporting them in the fight against religious racism, as well as providing information for Religious Education teachers and also for researchers in the area of Sciences of

1 O artigo foi recebido em 02 de junho de 2020 e aprovado em 19 de novembro de 2020 com base nas avaliações dos pareceristas ad hoc.

Este artigo é uma versão adaptada e ampliada de parte de um dos capítulos da tese de doutorado intitulada Afroteologia: construindo uma teologia das tradições de matriz africana, defendida por Hendrix Silveira na Faculdades EST, em 2019, sob a orientação do Prof. Dr. Oneide Bobsin.

2 Doutor. Bàbálórìsà da Comunidade Tradicional de Terreiro Ilé Asṣe Òrịsà Wúre. E-mail: hendrixsilveira@, yahoo.com.br

3 Doutor. Faculdades EST. E-mail: obobsin@est.edu.br 
Religion and Theology. Here we were able to build a vision of God in the traditions of African origin from a study of African and Afro-Brazilian sources, in addition to the oral tradition, the main means of transmitting knowledge by the traditional African communities.

Keywords: Theontology. Afrotheology. God. African-Brazilian religions.

\section{Introdução}

Em nossa dissertação de mestrado arrogamos a Teologia como uma área do conhecimento ampla e dinâmica, não sendo uma exclusividade da tradição cristã. Essa afirmação é importante, pois ainda hoje essa área é discriminada por outras, mesmo das chamadas Ciências Humanas, que se julgam mais científicas ou melhor adaptadas ao método científico.

No caso das tradições de matriz africana, este trabalho de pesquisa contribui para sua construção a despeito do questionamento de outras áreas do conhecimento que se advogam "mais apropriadas" a estudar esse "objeto".

Neste sentido, fomos arguidos por alguns pesquisadores de outras áreas que também vivenciam o Candomblé, em encontro promovido por nosso grupo de pesquisa ${ }^{4}$, quando os mesmos se encontravam em São Leopoldo para evento acadêmico a convite da Faculdades EST. Nesse encontro, tais pesquisadores se mostraram incomodados que nossa pesquisa se deu na área de Teologia e não na Antropologia, como é de praxe. Entrementes, entendemos que a Antropologia não é a "dona” das tradições de matriz africana e que essa disciplina não nos daria a instrumentalização que desejávamos para a compreensão teológica dessas tradições. Somente a Teologia nos subsidia nessa proposta, pois vemos as tradições de matriz africana como sujeito e não objeto de pesquisa, ou ainda como aponta Nascimento:

O enfoque antropológico, que em suas mais nobres expressões tenta respeitar o meio cultural estudado, detém-se, em geral, numa visão estática, localizando um grupo numa conjuntura e fixando-o como se estivesse preso para sempre à condição em que foi estudado. Esse enfoque, além de realçar o primitivo, obscurece os processos de fluxo e mudança que sempre caracterizaram a história africana ${ }^{5}$.

A Teologia proporciona a consciência da dinâmica desses processos de fluxo, mas há a falta de compreensão do que se trata essa área de conhecimento, pois muitos vivenciadores da tradição de matriz africana acadêmicos entendem que essa disciplina se resume à doutrinação eclesiástica.

Constantemente temos que explicar, em rodas de conversa, congressos, seminários, encontros, festas religiosas, grupos de estudos e em comunidades virtuais

4 Grupo de Pesquisa Identidade Étnica e Interculturalidade da Faculdades EST.

5 NASCIMENTO, Elisa Larkin. Sanfoka: significado e intenções. In: NASCIMENTO, Elisa Larkin (Org.). A matriz africana no mundo. São Paulo: Selo Negro, 2008. Cap. 1. p. 29-54. (Sankofa I). p. 49. 
específicas sobre o tema em redes sociais, que doutrina e Teologia não são a mesma coisa. Essa visão tacanha é preconceituosa com essa que já foi considerada a "rainha das ciências" em tempos idos. Parece-nos claro que a confusão é gerada pela visão típica do que seria o papel da Teologia na Idade Média, o que já não cabe nos dias de hoje.

Contudo, esses pesquisadores criticam qualquer tentativa de busca pela compreensão teológica das tradições de matriz africana, como diz o antropólogo cabo-verdiano e professor da Universidade Federal do Rio Grande do Sul, José Carlos Gomes dos Anjos, em documentário produzido por essa instituição:

Claro que sempre terão pessoas, intelectuais internos e externos à realidade afro-brasileira, que irão fazer um imenso esforço de sistematização dessa forma religiosa, mas o processo pelo qual a realidade afro-brasileira se constitui enquanto prática sacralizante, vai sempre escapar a essa tentativa de sistematização num todo doutrinário, ordenado, escrito e pode ser repassado de uma forma, digamos, sistemática ${ }^{6}$.

Todavia, os próprios antropólogos criam um tipo de sistematização ao descrever os rituais que presenciam e tentam interpretar, seja como outsiders ou insiders ${ }^{7}$, mas buscando um "distanciamento ético" de seu "objeto".

Temos entendido que, como área acadêmica, a Teologia se impõe como um estudo da complexidade dos elementos que compõem a fé vivenciada pela própria pessoa teóloga, de forma ética e crítica. Para tanto, os estudos teológicos cristãos se subdividem em vários tópicos como a Teologia Bíblica, a Teologia Histórica e a Teologia Sistemática, entre outros.

Segundo o teólogo e professor da Nazarene Bible College, Arnold E. Airhart, a Teologia Sistemática serve para "descrever a relação com Deus através da fé [...] de forma ordenada, estruturada e razoável". Serve para orientação "[...] com o objetivo de apresentar uma visão coerente e detalhada sobre Deus, os seres humanos e a relação redentora". Isso acontece por meio de uma "descrição ordenada, racional e coerente da fé e das crenças"

Com esse propósito, a Teologia Sistemática cristã se divide em várias áreas de estudos ou tópicos: a teontologia, a cristologia, a pneumatologia, a angelologia, a hagiologia etc.

6 CAMINHOS da Religiosidade Afro-Riograndense. Direção de Rafael Derois Santos. Produção de José Francisco da Silva. Porto Alegre: Infinite Filmes, 2015. (47 min.), son., color. Disponível em: <https:// youtu.be/_ao-1rP8TOo>. Acesso em: 21 out. 2019.

7 ENGLER, Steven; GARDINER, Mark Q. A filosofia semântica e o problema insider/outsider. Rever: Revista de Estudos da Religião, São Paulo, v. 10, n. 2, p. 89-105, set. 2010. Disponível em: < https://bit. ly/2CJJJZj>. Acesso em: 23 set. 2018.

8 AIRHART, Arnold E. Teologia sistemática. In: TAYLOR, Richard S.; GRIDER, J. Kenneth; TAYLOR, Willard H. (Ed.). Dicionário Beacon Teológico. Lanexa, Kansas: Casa Nazarena de Publicações, 1984. p. 795-796. 
Neste artigo propomos um estudo sobre o Ser Supremo de acordo com a cosmopercepção ${ }^{9}$ yorùbá ${ }^{10}$, buscando sistematizar o conhecimento adquirido por meio da tradição oral e registrado em obras tanto por autores africanos quanto por brasileiros e europeus, além de nossa vivência na tradição.

\section{Afroteontologia: conceituando}

A palavra teontologia é um neologismo criado pelo teólogo estadunidense Lewis Sperry Chafer (1871-1952) para definir a parte da Teologia Sistemática que estuda Deus. Também chamada de Teologia Própria, no cristianismo este estudo é específico do Ser de Deus, uma das manifestações do Ser Supremo entendido como trino para essa tradição religiosa.

Ao contrário do que costumeiramente é afirmado em fontes etnográficas, as tradições de matriz africana creem na existência de um único Ser Supremo, de um único Deus. Os etnógrafos costumam categorizar as tradições de matriz africana como politeístas devido à quantidade de divindades que são cultuadas em África. Mas chamamos a atenção ao fato de que, pelo menos no caso dos yorùbá, a visão de Deus é monoteísta, ou seja, há a crença na existência de um único Deus, um único Ser Supremo. Muitos antropólogos costumam usar o termo "Deus Supremo" para definir Olódùmarè, demonstrando um equívoco, pois essa expressão define a existência de vários deuses tendo um como o Supremo entre eles. Isso é contestado pelo antropólogo nigeriano Olúmúyiwá Anthony Adékọ̀yà:

9 Em sua tese de doutorado, a filósofa nigeriana e professora associada de Sociologia na Stony Brook University, Oyèrónkẹ́ Oyěwùmí faz uma crítica aos usos universais do conceito de cosmovisão. Ela cunhou a expressão "cosmosensação", ou "sentido do mundo" (world-sense), para marcar a diferença, em relação à percepção da realidade, entre os yorùbá, da "cosmovisão" ou "visão de mundo" (worldview) utilizada no Ocidente. O professor do Departamento de Filosofia da UnB e proprietário do site filosofiaafricana. com, Wanderson Flor do Nascimento, maior divulgador da filosofia africana no Brasil, traduz a expressão world-sense utilizada por Oyěwùmí como “cosmopercepção" por julgar que "a palavra 'sense', indica tanto os sentidos físicos, quanto a capacidade de percepção que informa o corpo e o pensamento". Segundo a autora, "o termo 'cosmovisão', que é usado no Ocidente para resumir a lógica cultural de uma sociedade, capta o privilégio ocidental do visual. É eurocêntrico usá-lo para descrever culturas que podem privilegiar outros sentidos. O termo 'cosmosensação' [ou cosmopercepção] é uma maneira mais inclusiva de descrever a concepção de mundo por diferentes grupos culturais”. OYĚWÙMÍ, Oyèrónkẹ́. The Invention of Women: making an African sense of western gender discourses. Minneapolis: University of Minnesota Press, 1997. p. 2-3.

10 As palavras em língua yorùbá que figuram neste trabalho estão escritas segundo a obra Uma abordagem moderna ao yorùbá (İDÒWÚ, 2011). A língua yorùbá é tonal e seu alfabeto é constituído por 25 letras: A B D E Ẹ F G GB H I J K L M N O Ọ P R S Ș T U W Y. Consoantes e vogais têm o mesmo valor que em português, porém a vogal E pronuncia-se sempre fechada, como em "ema", a E é sempre aberta como em "Eva". G tem som gutural como em "gado", e nunca como J. GB é explosivo. H é sempre pronunciado e tem som aspirado como em "hell” (inglês). A vogal O é fechado, como em "ovo" e Ọ é aberto como em "pó". R tem um som brando como em "rest" (inglês), nunca como RR. A consoante S é sibilante como em "sistema" e Ș é chiada como em "xícara" ou "chimarrão". W tem som de U e Y tem som de I. Não existem as consoantes C, Q, V, X e Z. A indicação do tom das sílabas é feita pela acentuação: grave indica tom baixo (dó), sem acento é tom médio (ré) e agudo indica tom alto (mi). 
Essa multiplicação de cultos e divindades pode levar à uma interpretação equivocada: a de que os Yorùbá servem a muitos deuses. Tal engano de interpretação encontra-se registrado em várias monografias e escritos difundidos acerca do assunto, quanto a distinção entre divindade e Deus, conferindo-lhes o sentido da visão de mundo ocidental e transferindo-a para as religiões africanas ${ }^{11}$.

Os òrị̀à não são deuses, e sim divindades ou seres divinos criados por Olódùmarè para fins específicos e que não carregam os atributos necessários para serem considerados deuses.

Entendendo que a teontologia de Deus de acordo com a cosmopercepção africana precisa ser estudada por um método que contemple suas especificidades, aderimos ao uso do prefixo "afro" na frente do substantivo para grifar a diferença.

Não temos certeza se todos os mais de oitocentos grupos étnicos africanos possuem uma visão monoteísta de Deus. Asante e Mazama apresentam uma imensa lista de nomes para o Ser Supremo que "foi compilada pelo estudioso e escritor Dr. Emeka Nwadiora da Temple University. Esses nomes foram coletados a partir de conhecimentos pessoais, referências literárias e narrativas orais"12. Entre esses nomes temos: Mawu, para os ewe; Nyame, para os fanti; Onyankopon, para os ashante; Mviri, para os ndongo; Kwoth, para os nuer; Kwamata, para os xosa; Unkulunkulu, para os zulu; Nzambi para os kuba e os lele; Zambiumpungu, para os vili; e para os yorùbá, Olódùmarè.

O Dr. James W. Peebles, fundador do Sankofa African Heritage Museum, afirma que não há como saber se todas as etnias africanas presumem a existência de um Deus único, mas que isso é perfeitamente observável dentre os yorùbá:

Uma visão mais ampla das religiões nativas africanas envolve uma gama de conceitos e preceitos. O continente africano é tão diversificado que tentar identificar uma religião africana em particular é bastante difícil, a menos que falamos a respeito de "Olódùmarè que é o Deus, ou Ser Supremo, para a maioria dos africanos. Mas esse termo pode ser usado em diferentes aspectos ou línguas que podem ser diferentes do Olódùmarè do povo yorùbá13.

Esse grupo étnico que ocupa um território extenso na África Ocidental, que possui a mesma cultura e língua, embora com diferentes dialetos e organização política descentralizada, compila algumas variações para o nome de Deus, tais como: Eledùmarè, Edùmarè e, talvez por influência cristã, também é chamado de Olúwa (Nosso Senhor) e Olọ́run (Senhor do Ọrun), pois os primeiros missionários cristãos

11 ADÉKÒYYÀ, Olúmúyiwá Anthony. Yorùbá: tradição oral e história. São Paulo: Terceira Imagem, 1999. p. 60.

12 [...] was compiled by the scholar and author Dr. Emeka Nwadiora of Temple University. These names are collected from personal knowledge, literary references, and oral narratives. ASANTE, Molefi Kete; MAZAMA, Ama. Appendix. In: ASANTE, Molefi Kete; MAZAMA, Ama. Encyclopedia of African religion. Thousand Oaks: Sage, 2009. p. 747. Tradução nossa.

13 RELIGIÕES africanas e afro-americanas. Direção de Coley Coleman. Intérpretes: Ben Kingsley. [s.1.]: Europa Filmes, 1999. 1 DVD (47 min.), NTSC, son., color. Legendado. Série História das Religiões. 
na África traduziam Ò̀run como Céu no sentido de espaço transcendente, onde mora o Deus cristão e sua corte de anjos e santos (Heaven). Além disso, ainda há vários epítetos como os enumerados no oríkì abaixo: ${ }^{14}$

L'ojú Olọ́run! L'ojú Olódùmarè!

Elẹdàá, Elẹẹmí, Olùpilẹṣẹ!

Oyígíyigi Ota Aikú

Ògàá Ògo Oba Òrun

Atẹrẹe K'áyé

Elẹni à tẹ $k a$

Oba a șè kan má kù

Olọ́run nikan l'ogbọn

Ar'inur'ode olùmọnokàn

Oba Airii Awamaridi

Oba Adáké dá'jọ

Oba mimo ti kò l'éèrí

Alalàfunfun òkè

Ișé Olọrun tóbi

Alábàáláàsẹ, a rán rere si i àwa
Na presença de Olórun! Na presença de Olódùmarè Criador, Senhor dos Espíritos, Senhor das Origens!

Pedra Imutável e Eterna Mais Alto Glorioso Rei do Òrun Aquele que Se espalha por toda a Terra

Dono da esteira que nunca se dobra Rei cujos trabalhos são feitos com perfeição

Olọ́run é o único que tem sabedoria Aquele que vê dentro e fora, e conhece os corações

Rei Invisível, que não podemos ver Rei que mora em cima, e que julga em silêncio

Rei puro, que não tem manchas O dono da roupa branca que está no mais alto Os trabalhos de Ọlọrun são poderosos Alábàáláàșẹ, envie coisas boas para nós

Além desses, Beniste ${ }^{15}$ também enumera outros: Alayé (Senhor da Vida), pois "lembra a condição de eternidade e poder sobre a vida", e Olọjọ́ Oní (Senhor do Dia de Hoje), pois Olódùmarè “está presente em todos os acontecimentos diários” como bem nos mostra o adùrá criado pelo próprio professor Beniste ${ }^{16}$ para o Curso Brasil-Nigéria de Língua Yorùbá e corrigido pelo professor Adébayọ Abìdemí Majarọ̀, que nos ministrou aulas dessa língua no curso Epistemologia negro-africana: pedagogia do axé, de que participamos em 2005:

Olọjọ́ Oní, mo júbà re o

Olọjọ́ Oní, mo júbà re o

E jẹ mi jiṣẹ

E jẹ mi jiṣè

Ti Olódùmarè rán mi

Bi Elẹmi kò gbà bá

Bi Elẹmi kò gbà bá

Olódùmarè Àsẹ

Olódùmarè Àșe

Olódùmarè a rán rere

Sí $i$ wao
Senhor deste dia, meus respeitos

Senhor deste dia, meus respeitos

Deixe-me cumprir a missão

Deixe-me cumprir a missão

Da qual Olódùmarè me encarregou Se o Senhor desta vida não o impedir Se o Senhor desta vida não o impedir

Olódùmarè nos dê sua aprovação

Olódùmarè nos dê sua aprovação

Possa Olódùmarè mandar sua bênção

Para o nosso trabalho

${ }^{14}$ MARINS, Luiz L. Obàtálá e a criação do mundo iorubá. São Paulo: Ed. do Autor, 2013. p. 7.

${ }^{15}$ BENISTE, José. Ọrun-Àiyé, o encontro de dois mundos: o sistema de relacionamento nagô-yorubá entre o céu e a Terra. 6. ed. Rio de Janeiro: Bertrand Brasil, 2008. p. 29.

${ }^{16}$ BENISTE, 2008, p. 43. 
Este estudo foca em Olódùmarè justamente por guardar esses atributos que estão aquém daqueles que as divindades detêm. Basta-nos afirmar, por agora, que os òrị̀à são manifestações de Olódùmarè, mas não são ele mesmo.

\section{Origens e atribuições do Ser Supremo}

Já vimos que Deus possui muitos nomes e epítetos. O nome é algo muito importante para os yorùbá. Os nomes sempre têm um sentido, uma atribuição ou relação com a vida de quem o carrega. Existem algumas tentativas de identificar a origem etimológica do nome Olódùmarè; José Beniste sugere que seja olu +odù + marè. Olu significa "senhor" no sentido de "dono"; odù "pode ter o significado de tudo aquilo que é muito grande, muito extenso"; marè é algo imutável. ${ }^{17}$ Já para Olọ́run, Santos apresenta um conceito:

Ọlọ́run, entidade suprema, o + ni + ọ̀run, aquele que é ou possui ọ̀run, não é apenas um deus ligado ao céu como o pretendem certos autores, mas aquele que é ou possui todo o espaço abstrato paralelo ao àiyé, senhor de todos os seres espirituais, das entidades divinas, dos ancestrais de qualquer categoria e dos dobles espirituais de tudo o que vive ${ }^{18}$.

Como já expusemos antes, Olódùmarè é o Deus único, o que caracterizaria essa tradição como monoteísta. Contudo, alguns pesquisadores "desde dentro", levados por um sentimento de rechaço a tudo que possa remeter ao cristianismo nessa tradição, levantaram a suspeita de que ela seria henoteísta. No henoteísmo, Deus cria a Terra e os seres humanos e depois se aparta da criação, deixando-a aos cuidados de deuses menores.

O problema com essa interpretação é que ignora que Olódùmarè não se afasta da Criação. Ele se mantém presente como bem nos mostra um cântico popular que aprendemos no curso Epistemologia negro-africana: pedagogia do axé, na disciplina de Introdução ao Idioma Yorùbá, ministrado pelo Prof. Adébayọ Abìdemí Majarọ̀: ${ }^{19}$

$O$ șeun fún mi

$O$ șeun fún mi

Ohun bàbá o le șe

Èdùmarè șe é fún mi o
Ele faz para mim

Ele faz para mim

O que meu pai não consegue fazer

Edùmarè faz para mim

17 BENISTE, 2008, p. 28.

18 SANTOS, Juana Elbein dos. Os nàgó e a morte: pàdé, àșẹșẹe e o culto égún na Bahia. 11. ed. Petrópolis: Vozes, 2002. p. 56.

${ }^{19}$ Como aconteceu em grande parte deste trabalho, tivemos o auxílio do Prof. Gideon, que nos tirou muitas dúvidas. Sobre essa canção ele me escreveu: "Devemos desconsiderar [na tradução a palavra] 'gbàlàjà', pois não tem equivalência lógica em português, só explica a maneira que abrimos as mãos para receber coisas boas ou dádiva oferecida por Deus". İDÒWÚ, Gideon Babalọlá. Escrita yorùbá e tradução de canção sobre Olódùmarè. [mensagem pessoal] Mensagem recebida por<@hendrixsilveira> em: 04 nov. 2019. 
Ma tệọ́ gbàlàjà

Ma tẹwó gba're

Ire owo

Ire omo

Ire àlàáfià

Șe bí Elédùmarè ni o bàbá

Ejọ o ooooo

Ohun bàbá o le șe

Èdùmàrè șe fun mi o
Estendo minhas mãos

Estendo minhas mãos para receber coisas boas

Bom dinheiro

Bons filhos

Boa sorte

Ele é o Pai Todo-Poderoso

Não atrapalhe a minha oração

$\mathrm{O}$ que meu pai não consegue fazer

Edùmarè faz para mim

Essa cantiga popular deixa claro que Olódùmarè não está aquém do mundo, mas sim que está presente e atento aos anseios dos seres humanos. Por isso lhe é conferido vários atributos dos quais Beniste ${ }^{20}$ e Awolalu ${ }^{21}$ elencaram e que apresentamos a seguir de forma resumida.

Ele é o Criador ainda que quem tenha efetivamente criado a Terra e os seres humanos seja Oșàálá, este só pode realizá-lo graças aos poderes que Olódùmarè lhe conferiu. Além disso, os seres humanos só vivem por causa do ẹmí que ele - e somente ele - lhes dá. Por ser o Criador, ele também é Único, pois como diz Awolalu:

Isso significa que Ele é o único e não há outro como Ele. É em consequência de Sua singularidade que o povo não esculpe imagens nem $\mathrm{O}$ pintam. Existem símbolos ou emblemas, mas nenhuma imagem, pois nada pode ser comparado a Ele. Essa pode ser uma das razões pelas quais investigadores estrangeiros da religião do povo [yorùbá] cometeram o erro de pensar que Ele é um Deus afastado, sobre quem os seres humanos estão incertos (Deus remotos et incertus) ${ }^{22}$.

Olódùmarè também é o único ser que é imortal, pois ao contrário do que se pode imaginar, os òrișà são mortais. Vários itàn relatam as divindades fugindo de $I k u$, a Morte, o que demonstra que eles não são eternos como o é Olódùmarè. Ao contrário dos òriṣà que precisam ser cultuados para se manter vivos e assim também manter a criação viva, pois sem os òrị̦à toda a vida na Terra morre. Olódùmarè está acima disso tudo, pois não faz sentido que o Senhor da Vida possa perder a sua própria. Além disso, foi ele quem criou Ikú (a Morte) e este não poderia ter poderes maiores que o de seu próprio Criador. Olódùmarè também não precisa de cultos, oferendas ou sacralizações. Nada que os seres humanos criem ou façam pode influenciá-lo. Não há templos, sacerdotes ou ritos específicos para o Ser Supremo, pois por ser supremo, tudo lhe pertence, e a única coisa que podemos lhe ofertar é nosso compromisso sagrado. Contudo, isso não significa que ele está apartado de nós, como já mencionamos

${ }^{20}$ BENISTE, 2008, p. 29-37.

21 AWOLALU, J. Ọọșade. Yorùbá beliefs and sacrificial rites. New York: Athelia Henrietta Press, 1996. p. 12-19.

22 This means that He is the One and there is no other like Him. It is in consequence of His uniqueness that the people have no graven images or pictorial painting of Him. There are symbols or emblems of Him but no images, for nothing can be compared to Him. This may be one of the reasons why foreign investigatiors of the people's religion have made the mistake of thinking that He is a withdrawn God about whom men are uncertain (Deus remotus et incertus). AWOLALU, 1996, p. 14. Tradução nossa. 
antes; ele é Deus, e como Deus, está atento a tudo e a todos, logo, pode atender, por meio dos òrị̀à, nossas súplicas.

Os três atributos mais conhecidos de Deus são a sua onipotência, onisciência e onipresença. Ser onipotente significa que ele tem poderes de realização que envolve toda a gama de coisas imagináveis e inimagináveis. Seu poder transcende qualquer realidade, logo, pode fazer o que quiser. Claro que o paradoxo de Epicuro ${ }^{23}$ permanece inalterável sobre essas condições, mas nada impede digressões a esse respeito que pretendemos trabalhar no futuro.

Olódùmarè é chamado de "Todo-Poderoso" (Alàgbára) pelos yorùbá. Isso até pode ser de influência cristã ou islâmica, afinal essas duas religiões estão presentes na África Ocidental há gerações ${ }^{24}$, mas certamente é a percepção dos africanos sobre o Ser Supremo que permitiu que essas hibridizações culturais pudessem acontecer. Assim, vários oriki atestam sua onipotência:

Oba a șè kan má kù

A dùn ișe bi ohun tí Olódùmarè lộwọ sí, a șòro ișe bi ohun tí Olódùmarè lộwó sí

Oba tí dandan rẹ ki ísélè

Aisàn ló dùn íwò, a kò ri tọlọjọ șè
O Rei cujas licitações nunca deixam de ser atendidas Algo é fácil de fazer quando Olódùmarè aprova; difícil é fazer aquilo que o Olódùmarè não sanciona

O Rei cujas obras são feitas com perfeição A doença pode ser curada, mas a morte predeterminada não pode ser evitada

Esse último orikì pode sugerir que Olódùmarè não tem controle sobre a morte, o que seria um equívoco. Awolalu deixa isso claro:

A implicação dessa afirmação é que os yorùbá acreditam que Olọjọ (o Controlador dos eventos diários), outro nome para o Ser Supremo, pré-determinou o que acontecerá com todos em todos os momentos de sua vida aqui na Terra, inclusive quando ele morrerá. Se uma pessoa está doente, ela pode ser facilmente curada se a hora marcada da morte ainda não tiver chegado; mas a hora da morte sancionada por Olọjọ́ não pode ser evitada. Isso é para enfatizar Sua onipotência ${ }^{25}$.

${ }^{23}$ O paradoxo de Epicuro (341-270 a.C.) se refere ao problema da existência do mal num mundo em que há um Deus que seja onipotente, onisciente e benevolente. O filósofo grego busca analisar essas três atribuições de Deus, tal qual o Deus judaico. Sua lógica propõe que se duas dessas atribuições forem verdadeiras, uma delas será automaticamente falsa. Segundo Epicuro: se Deus sabe da existência do mal e pode acabar com ele, mas não o faz, então não é benevolente; se é benevolente e tudo pode, então não sabe da existência do mal, logo não é onisciente; mas se sabe da existência do mal, é benevolente, mas não consegue destruí-lo, é porque não é onipotente. TOOLEY, Michael. The problem of evil. Stanford encyclopedia of philosophy. Disponível em: $<$ http://plato.stanford.edu/entries/evil/>. Acesso em: 02 jun. 2019.

${ }^{24} \mathrm{O}$ cristianismo está na região há pelo menos cinco séculos, enquanto que o islamismo há mais de mil anos.

${ }^{25}$ The implication of this statement is that the Yorùbá believe that Olọjọ (the Controller of daily events), another name for the Supreme Being, has pre-determined what will happen to everybody in every moment of his life here on earth, including when he will die. If a person is ill, he can easily be cured if the appointed time of death has not yet come; but a time of death sanctioned by Olójọ cannot be averted. This is to emphasise His omnipotence. AWOLALU, 1996, p. 15. Tradução nossa. 
Assim como é onipotente, Olódùmarè também é onisciente. A onisciência significa que ele é o Senhor que sabe de tudo. Alguns itàn falam de Olódùmarè consultando Ifá para saber o que fazer. Isso fez com que alguns estudiosos - inclusive insiders com formação em outras áreas que não a Teologia - entenderem que ele não é onisciente, pois precisa consultar Òrúnmilà. Certamente esses estudiosos não entenderam a premissa da importância da consulta ao oráculo sagrado. O povo yorùbá não toma qualquer decisão em suas vidas sem antes consultar Ifá e os itàn, que falam que até mesmo Olódùmarè o consulta é apenas um demonstrativo de sua importância. Mas não devemos nos enganar, toda sabedoria e conhecimento que Òrúnmilà possui lhe foi entregue por Olódùmarè, ou seja, o conhecimento enquanto poder é uma dádiva de Deus à Òrúnmilà, que o concede aos seres humanos para guiar-lhes a vida. Alguns oriki e provérbios remetem à sua onisciência:

Eléti ìgó àròyé

A'rinú-róde olùmo okàn

Ohun tí ó pamó, ojú Olọrun tó

Olọ́run ló gbọn, ẹdá gọ púpọ
O que está escondido para as pessoas é visto pelos olhos de Olọ́run Aquele que sabe o interior e o exterior do coração das pessoas Aquele que está sempre ouvindo as reclamações das pessoas Deus é sábio, as criaturas são muito ignorantes

Outro atributo dessa "tríade" é a onipresença. Aqui apontamos mais uma vez que os òriṣà não são onipresentes, pois precisam ser invocados por meio de ritos específicos. Olódùmarè nunca é invocado, não é necessário, pois ele está em todo lugar. O mundo é seu e ele pode estar em qualquer lugar que desejar. "Ele pode ser chamado a qualquer momento e em qualquer lugar porque é onipresente. Em outras palavras, Sua transcendência não descarta Sua imanência."’26

Também lhe são atribuídos poderes de Rei e Juiz Supremo. Esses postos hierárquicos humanos são explicados por Beniste como sendo uma antropomorfização de Deus, mas defendemos que o que existe é o contrário, uma teomorfização dos seres humanos, assim não apenas os seres humanos são feitos "à imagem e semelhança" de Deus, mas todas as atividades humanas e a organização social é uma "imitação" daquela que existe no Ọrun. Olódùmarè é o Rei Supremo, o Rei de todos os Reis, cuja majestade é única e incomparável. Como Rei, também exerce a função de Juiz, daí se referirem a ele como "Oba a dáké dájọ", "o Rei que se senta em silêncio e aplica a justiça". Alguns itàn mostram Olódùmarè resolvendo contendas entre os Òrìsà, além de seu papel no İdájọ, o julgamento final, no qual os mortos prestam reverência à sabedoria de Olódùmarè, aguardando a definição de seu destino final num dos espaços de Ọrun.

Olódùmarè é transcendente e sagrado, por isso há um imenso respeito por ele. Deus não pertence a este mundo, mas o mundo lhe pertence. Ele não é um deus da natureza, nem um entre muitos; é o "totalmente outro" no sentido atribuído por Susin $^{27}$ a Deus, com base em Lévinas. Mas ser o "totalmente outro" não significa que

${ }^{26}$ He can be called upon any time and anywhere because He is omnipresent. In other word, His transcendence does not rule out His immanence. AWOLALU, 1996, p. 16. Tradução nossa.

27 SUSIN, Luiz Carlos. O homem messiânico: uma introdução ao pensamento de Emmanuel Levinas. Petrópolis: Vozes, 1984. 488 p. Ganz andere pode ser traduzido como "totalmente outro" conforme Rudolf Otto. Deus ou o Sagrado não podem ser reduzidos a conceitos racionais. “'Totalmente outro’, celestial, 
sua relação com o mundo seja de "afastamento". Segundo Awolalu ${ }^{28}$, a relação entre Olódùmarè e os seres humanos está mais vinculada com a cultura yorùbá, que é extremamente hierarquizada, na qual os filhos, quando têm problemas a resolver, falam com a mãe e essa é que chegará ao pai. Isso não significa que exista um respeito maior pelo pai, pois o respeito pela mãe é idêntico, mas sim que na hierarquia social yorùbá os filhos não podem chegar diretamente ao pai senão por meio da mãe. A premissa ocidental de "para que ir aos santos se posso ir a Deus" é totalmente antiética na percepção de mundo yorùbá. Exatamente o mesmo ocorre com a relação entre os seres humanos e Olódùmarè: nós devemos, por um comportamento ético, chegar a Deus por meio das divindades que ele criou, os Òìsà.

\section{Considerações finais}

Propomos, neste artigo, conhecer um pouco mais a figura de Deus nas tradições de matriz africana e suas relações com o mundo e com as demais divindades sobre a ótica da afroteologia, ou seja, com bases epistemológicas da percepção de mundo africana e afro-brasileira.

Apresentamos nossa afroteontologia como uma proposta de conhecimento sobre o Ser Supremo africano, com ênfase na percepção yorùbá. Também fizemos uma breve análise sobre suas origens e natureza.

Certamente que não buscamos exaurir, com este estudo, as possibilidades de interpretação e entendimento sobre o pensamento africano a respeito do Ser Supremo e seus desdobramentos, mas sim que se faz necessária uma investigação mais atenta a essa realidade. Um dos desdobramentos é justamente a manifestação dos òrișà.

Entendemos que Olódùmarè é Deus na acepção conceitual do termo. É a forma como os africanos veem a origem de todas as coisas. Que ele não é nem bom nem mal, pois paira acima dessas forças. Que o mal e seus agentes não são fruto de Deus, mas que são combatidos pelos òrị̀à que, em última instância, são os modelos pelos quais devemos seguir com uma vida ética e moralmente aceita em prol da comunidade.

\section{Referências}

ADÉKỌ̀YÀ, Olúmúyiwá Anthony. Yorùbá: tradição oral e história. São Paulo: Terceira Imagem, 1999. $176 \mathrm{p}$.

AIRHART, Arnold E. Teologia sistemática. In: TAYLOR, Richard S.; GRIDER, J. Kenneth; TAYLOR, Willard H. (Ed.). Dicionário Beacon Teológico. Lanexa, Kansas: Casa Nazarena de Publicações, 1984. p. 795-796.

contraponto a tudo o que existe aqui e agora." Desconsiderando a causalidade ou hierarquia entre as religiões, podemos ver afinidades entre a compreensão de Otto sobre Deus judaico, cristão e muçulmano e a cosmopercepção de nosso artigo. OTTO, Rudolf. O sagrado: os aspectos irracionais na noção do divino e sua relação com o racional. Trad. Walter O. Schlupp. 2. ed. São Leopoldo: Sinodal, 2011. p. 121.

${ }_{28}$ AWOLALU, 1996, p. 17. 
ASANTE, Molefi Kete; MAZAMA, Ama. Appendix. In: ASANTE, Molefi Kete; MAZAMA, Ama. Encyclopedia of African religion. Thousand Oaks: Sage, 2009. p. 747-749.

AWOLALU, J. Ọọșade. Yorùbá beliefs and sacrificial rites. New York: Athelia Henrietta Press, 1996. 230 p.

BENISTE, José. Ọrun-Àiyé, o encontro de dois mundos: o sistema de relacionamento nagô-yorubá entre o céu e a Terra. 6. ed. Rio de Janeiro: Bertrand Brasil, 2008. 336 p.

CAMINHOS da Religiosidade Afro-Riograndense. Direção de Rafael Derois Santos. Produção de José Francisco da Silva. Porto Alegre: Infinite Filmes, 2015. (47 min.), son., color. Disponível em: <https://youtu.be/_ao-lrP8TOo>. Acesso em: 21 out. 2019.

ENGLER, Steven; GARDINER, Mark Q. A filosofia semântica e o problema insider/outsider. Rever: Revista de Estudos da Religião, São Paulo, v. 10, n. 2, p. 89-105, set. 2010. Disponível em: $<$ https://bit.ly/2CJJJZj>. Acesso em: 23 set. 2018.

ÌDÒWÚ, Gideon Babalọlá. Escrita yorùbá e tradução de canção sobre Olódùmarè. [mensagem pessoal] Mensagem recebida por<@hendrixsilveira> em: 04 nov. 2019.

. Uma abordagem moderna ao yorùbá (nagô): gramática, exercícios, minidicionário. 2. ed. Porto Alegre: Ed. do Autor, 2011. 256 p. Com CD.

MARINS, Luiz L. Obàtálá e a criação do mundo iorubá. São Paulo: Ed. do Autor, 2013. 120 p. NASCIMENTO, Elisa Larkin. Sanfoka: significado e intenções. In: NASCIMENTO, Elisa Larkin (Org.). A matriz africana no mundo. São Paulo: Selo Negro, 2008. Cap. 1. p. 29-54. (Sankofa I). OTTO, Rudolf. O sagrado: os aspectos irracionais na noção do divino e sua relação com o racional. Trad. Walter O. Schlupp. 2. ed. São Leopoldo: Sinodal, 2011.

OYĚWÙMÍ, Oyèrónkẹ́. The Invention of Women: making an African sense of western gender discourses. Minneapolis: University of Minnesota Press, 1997.

RELIGIÕES africanas e afro-americanas. Direção de Coley Coleman. Intérpretes: Ben Kingsley. [s.1.]: Europa Filmes, 1999. 1 DVD (47 min.), NTSC, son., color. Legendado. Série História das Religiões.

SANTOS, Juana Elbein dos. Os nàgó e a morte: pàdé, àșẹșẹ̀ e o culto égún na Bahia. 11. ed. Petrópolis: Vozes, 2002. 264 p.

SUSIN, Luiz Carlos. O homem messiânico: uma introdução ao pensamento de Emmanuel Levinas. Petrópolis: Vozes, 1984. 488 p.

TOOLEY, Michael. The problem of evil. Stanford encyclopedia of philosophy. Disponível em: $<$ http://plato.stanford.edu/entries/evil/>. Acesso em: 02 jun. 2019. 